University of Wollongong

Research Online

Faculty of Engineering - Papers (Archive)

Faculty of Engineering and Information

Sciences

$1-1-2006$

\title{
An evaluation of airborne laser scan data for coalmine subsidence mapping
}

D. R. Palamara

University of Wollongong, danielp@uow.edu.au

M. Nicholson

BHP Billiton Illawarra Coal

Phil Flentje

University of Wollongong, pflentje@uow.edu.au

E. Baafi

University of Wollongong, ebaafi@uow.edu.au

G. Brassington

BHP Billiton Illawarra Coal

Follow this and additional works at: https://ro.uow.edu.au/engpapers

Part of the Engineering Commons

https://ro.uow.edu.au/engpapers/306

\section{Recommended Citation}

Palamara, D. R.; Nicholson, M.; Flentje, Phil; Baafi, E.; and Brassington, G.: An evaluation of airborne laser scan data for coalmine subsidence mapping 2006.

https://ro.uow.edu.au/engpapers/306

Research Online is the open access institutional repository for the University of Wollongong. For further information contact the UOW Library: research-pubs@uow.edu.au 


\title{
An evaluation of airborne laser scan data for coalmine subsidence mapping
}

\author{
D.R. PALAMARA*§, M. NICHOLSON\$, P. FLENTJE§, E.BAAFI§, and G.M. BRASSINGTON\$ \\ $\S$ University of Wollongong, School of Civil, Mining, and Environmental Engineering, Australia \\ \$BHP Billiton, Illawarra Coal, Australia.
}

*Corresponding author. Email: danielp@uow.edu.au

The accurate mapping of coalmine subsidence is necessary for the continued management of potential subsidence impacts. The use of airborne laser scan (ALS) data for subsidence mapping provides an alternative method to traditional ground-based approaches that affords increased accessibility and complete spatial coverage. This paper evaluates the suitability and potential of ALS data for subsidence mapping, primarily through the examination of two pre-mining surveys in a rugged, densely vegetated study site. Data quality, in terms of mean point spacing and coverage, is evaluated, along with the impact of interpolation methods, resolution, and terrain. It was assumed that minimal surface height changes occurred between the two premining surfaces. Therefore any height changes between digital elevation models of the two ALS surveys were interpreted as errors associated with the use of ALS data for subsidence mapping. A mean absolute error of $0.23 \mathrm{~m}$ was observed, though this error may be exaggerated by the presence of a systematic $0.15 \mathrm{~m}$ offset between the two surveys. Very large (several metres) errors occur in areas of steep or dynamic terrain, such as along cliff lines and watercourses. Despite these errors, preliminary subsidence mapping, performed using a third, post-mining dataset, clearly demonstrates the potential benefits of ALS data for subsidence mapping, as well as some potential limitations and the need for further careful assessment and validation concerning data errors.

Keywords: Airborne Laser Scan, Subsidence, Mining

\section{Introduction}

Airborne laser scan (ALS) data offer superior vertical accuracy and dense horizontal coverage over large areas, and are therefore often used in surface morphology and height change analyses that require highresolution topographic data (Lohani and Mason, 2001; Woolard and Colby, 2002; Shrestha et al., 2005; Thoma et al., 2005; Glenn et al., 2006). For mapping coalmine-induced subsidence, ALS data potentially offers a number of distinct advantages over traditional, ground-based surveys. Foremost is the ability to survey areas where access is difficult due to rugged terrain, dense vegetation, or administrative reasons. More importantly, however, ALS data can potentially be used to produce a complete map of subsidence over the entire subsidence-affected area for a given time period, which facilitates a better understanding of the extent and magnitude of subsidence compared to isolated survey lines. A further benefit is that large volumes of data can be collected without the need to use resource intensive ground survey methods. Furthermore, the premining ALS data can be used for the purpose of site characterisation and topographical feature identification, which is often required for comprehensive impact assessment and coalmine development approval processes.

The goafing (caving) of longwalls as mining progresses along a panel is expressed at the ground surface and subsurface as vertical and horizontal ground movements, known as subsidence. In the coalfields of NSW the majority of longwall mining induced subsidence generally occurs immediately after goafing, with only some 
residual settling persisting for months or years later (Waddington and Kay, 1995). Subsidence is an important and often negative impact of coalmining and can cause damage to both natural and man-made features such as cliffs, watercourses and aquifers, buildings, pipelines, roads, and railways (Bell et al., 2000; Sidle et al., 2000). The need to monitor subsidence stems mainly from the need to verify the subsidence predictions that are commonly calculated prior to mining to gauge potential subsidence impacts. The magnitude of vertical ground movement associated with longwall subsidence is influenced by a number of factors including mining geometry, topography, and geology (Holla and Barclay, 2000). Consequently, mining-induced subsidence can range from sub-metre movements (Singh and Singh, 1998) to tens of metres (Bell et al., 2000). Given the instrumental accuracy of ALS data (typically $\sim 15 \mathrm{~cm}$ ), it is evident that careful consideration of methodologies may be required in order to reliably map subsidence, particularly when the magnitude of the expected subsidence is small.

This paper uses two pre-mining ALS surveys over a coalmine longwall panel to examine the suitability of the data for subsidence mapping purposes. The main objective is to determine ALS 'data quality', where data quality (Smith et al., 2005) is taken to mean the appropriateness of the data for the proposed task. This is done by determining how accurately ALS data can quantify the extent and magnitude of height changes between repeat surveys. Our aim is not to determine the accuracy of the ALS data for ground mapping purposes, only to determine what the capabilities and limitations of the this technique are for mapping surface height changes in areas when ground survey methods are not feasible. Accordingly, the issues that warrant investigation are those that are likely to introduce error and uncertainty into the final subsidence map, which can be intrinsic to the raw data (such as instrumental accuracy and precision between surveys, i.e., repeatability), introduced as part of the analysis process (interpolation and resolution errors), or associated with the ground surface such as changes in heights during mining that are unrelated to subsidence, or complications due to rough terrain. A preliminary subsidence map is also presented using a third, post-mining ALS survey which highlights the potential of this approach for subsidence mapping as well as pertinent limitations.

\section{Site Description}

The study site measures roughly $1.5 \mathrm{~km}$ by $4.3 \mathrm{~km}(\sim 6.5 \mathrm{~km} 2)$ and is situated near the city of Wollongong, roughly $80 \mathrm{~km}$ south of Sydney in the state of New South Wales, Australia. Coking coal was extracted from a longwall within the study area between April 2005 and December 2005. The coal was mined from the Wongawilli seam, which has a working thickness of $\sim 3.1 \mathrm{~m}$ and a depth of cover from 175 to $315 \mathrm{~m}$ (average of $\sim 262 \mathrm{~m}$ ) at the location of the longwall under consideration. The maximum expected subsidence was in the order of $2.4 \mathrm{~m}$.

A 3D representation of the surface over the coalmine, draped with a high-resolution aerial image, (Figure 1) shows that the study area is heavily vegetated and that the terrain is rugged. Numerous cliffs, approximately $20 \mathrm{~m}$ in height, flank the ridge in the centre of the study area and the adjacent slopes can be considered 'steep' to 'very steep' according to the classification system of McDonald et al. (1998). Consequently, the study site is not easily accessible for traditional, ground-based subsidence surveying purposes and presents a suitable site for the investigation of alternative methods of subsidence mapping. The site is particularly suitable because the same hindrances that apply to ground based surveys can also affect the collection of ALS data, though on a lesser scale. Dense vegetation cover can mask the ground surface, while the representation of steep terrain in ALS data can be compromised by relatively limited horizontal accuracy of the data. The results can therefore be viewed as a comprehensive evaluation of the potential of ALS data for measuring mine subsidence in challenging, rugged terrain. 


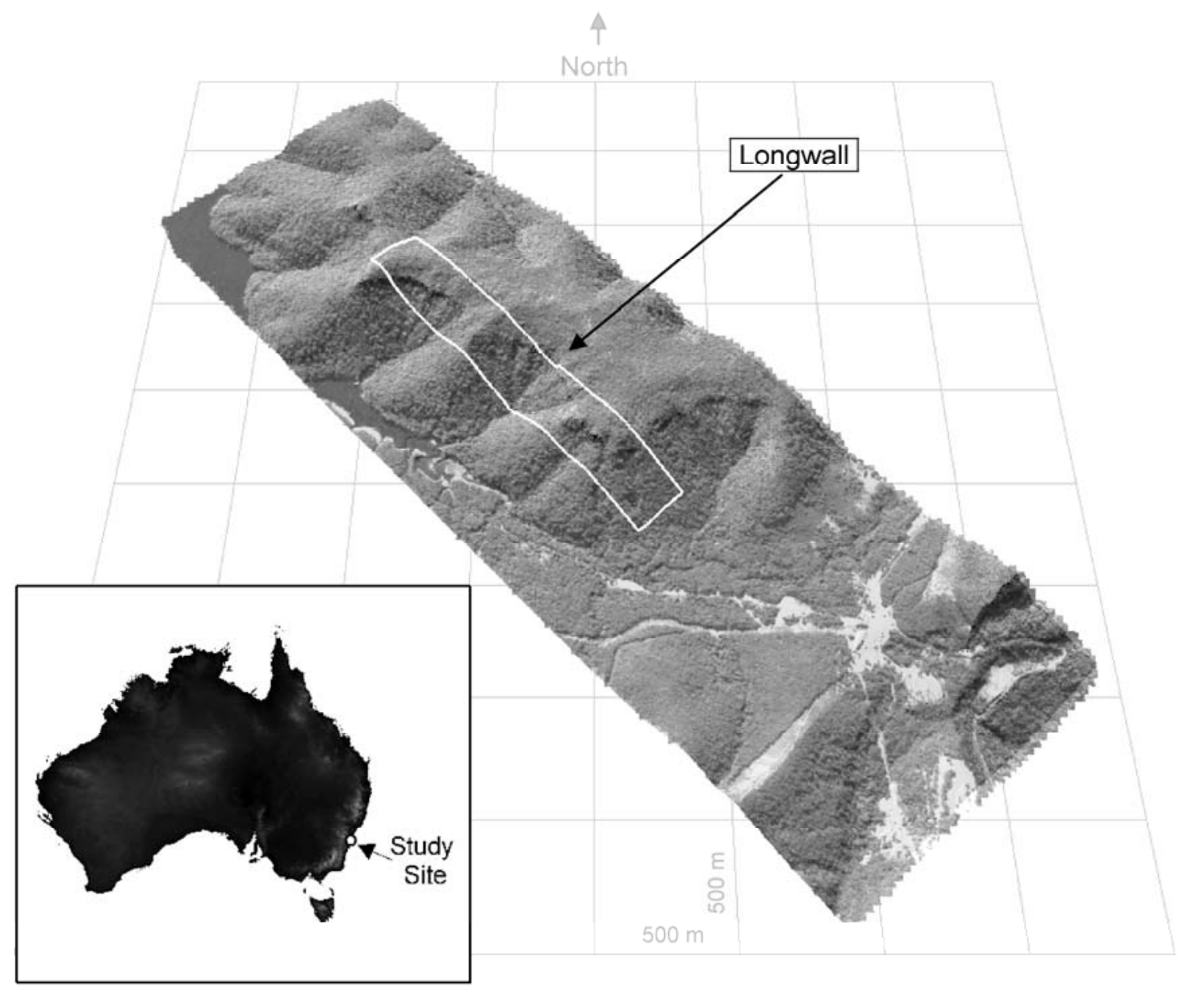

Figure 1. The study area. The surface projection of the longwall panel is indicated (approximately) by the white polygon. The gridline spacing is $500 \mathrm{~m}$ in both directions; the figure is oriented with north at the top of the grid. The figure demonstrates that the study site is rugged and densely vegetated, and is therefore a challenging site for all forms of subsidence mapping, including ALS.

\section{ALS Parameters}

It is acknowledged that there are a number of key parameters which affect the absolute accuracy of ALS data. Many of these variables are associated with ALS data acquisition, such as: flying height, swathe angle, flight line orientation, flight line overlaps, proximity of GPS base station(s), to name a few. In addition to the acquisition based parameters there a similar number of data reduction variables will directly impact upon the final ALS dataset; data editing methodologies, data filters, methods of tying individual flight lines into contiguous block(s), integration of ground surveyed calibration data, and so on. ALS parameters are selected based on the intended use of the data, accuracy required, point density required, topography, vegetation cover, prevailing weather, airspace constraints and of course cost. Whilst it is not the intention of the paper to explore the impact that variations in these parameters make during both the acquisition phase and subsequent data reduction processes, it is recognised that they play a key role in the accuracy and validity of the final 
dataset. It should also be acknowledged that ALS is still an emerging technology, and as such significant advances are being made with respect to hardware, acquisition methodologies and processing techniques.

\section{Data and Methods}

The two datasets used in the evaluation of the potential of ALS data to map coalmine subsidence are described in Table 1, and correspond to two separate surveys over the coalmine area conducted prior to mining. The original data consist of XYZ ASCII files of filtered ALS data, for which the data provider has removed non-ground strikes. The suitability of the ALS data for subsidence mapping was determined by comparing the height changes between the two pre-mining surveys, in the same manner that pre- and postsubsidence surveys would be compared in order to map subsidence.

Table 1. Source data parameters

\begin{tabular}{|c|c|c|c|c|c|c|c|}
\hline $\begin{array}{c}\text { Dataset } \\
\text { No. }\end{array}$ & Label & $\begin{array}{c}\text { Date } \\
\text { Collected }\end{array}$ & Instrument & $\begin{array}{l}\text { Nominal } \\
\text { Accuracy } \\
\text { (vertical) }^{1}\end{array}$ & $\begin{array}{c}\text { Nominal } \\
\text { Accuracy } \\
\text { (horizontal) }^{1}\end{array}$ & $\begin{array}{c}\text { Mean } \\
\text { Point } \\
\text { Separation }^{2} \\
\text { (metreș) }\end{array}$ & $\begin{array}{l}\text { Number } \\
\text { of points }\end{array}$ \\
\hline 1 & $\begin{array}{c}\text { Baseline } \\
2003 \\
\end{array}$ & $10-05-03$ & $\begin{array}{c}\text { Optech } \\
3025\end{array}$ & $0.15 \mathrm{~m}$ & $<0.55 \mathrm{~m}$ & $\begin{array}{c}1.69(\mathrm{~s} . \mathrm{d} .= \\
0.58)\end{array}$ & 770,311 \\
\hline 2 & $\begin{array}{c}\text { Baseline } \\
2005\end{array}$ & $15-02-05$ & $\begin{array}{c}\text { Optech } \\
3025\end{array}$ & $0.15 \mathrm{~m}$ & $<0.55 \mathrm{~m}$ & $\begin{array}{c}1.85 \text { (s.d. }= \\
0.90)\end{array}$ & 479,461 \\
\hline
\end{tabular}

\footnotetext{
${ }^{1}$ Accuracy data acquired from the ALS metadata.

${ }^{2}$ Calculated using Golden Software's Surfer 8.0, on the entire sample. The removal of $5 \%$ of the original points for the purpose of split-sample validation increased the mean point separation to $1.71 \mathrm{~m}$ and $1.88 \mathrm{~m}$ respectively.

${ }^{3}$ Includes the $5 \%$ of points removed for split-sample analyses
}

The two baseline surveys were conducted two years apart and the magnitude of the change in surface height in this time, due to natural processes, is expected to be minimal. This is because the study site occurs in an administrative zone designated as 'catchment land', which prohibits public access and development. The site is therefore heavily vegetated and it is assumed that limited surface change due to erosion or deposition has occurred throughout the majority of the site, particularly since near-drought conditions have prevailed in the region during this time. Furthermore, the study site is situated on the Woronora plateau, which is part of the dissected and tectonically stable Permian-Triassic sedimentary Sydney Basin (Haworth, 2003). As well as tectonic stability, the analysis of sediments from numerous upland swamps on the Triassic Hawkesbury Sandstone of the plateau suggests that there have been no substantial changes in hydrology or sedimentary processes since the late Pleistocene (Young, 1986). However, confirmation of an absence of widespread erosion or deposition in the study area was not possible due to a lack of site access, and the view that there has been little or no vertical ground movement between the two baseline surveys therefore remains an assumption on our part. With the assumption, therefore, that a comparison of the 2003 and 2005 baseline surfaces should yield minimal height change, particularly when compared to the magnitude of the expected mine subsidence, any departure from this is assumed to be primarily the result of limitations in the ALS mapping process arising from issues intrinsic to the ALS data or due to the methodology deployed. In documenting these spurious changes we aim to develop a better understanding of ALS capabilities for surface height change analyses, which can then be used to for a priori assessments of ALS feasibility for future subsidence surveys. 
It should be noted that the scope of the 2003 ALS survey was NOT to be the baseline series for the monitoring of mine subsidence; rather the 2003 survey was commissioned primarily to define the full supply level (FSL) of a nearby dam. As such some of the data acquisition and processing parameters differ from those adopted for the specific subsidence ALS surveys of February 2005 and December 2005.

Since the location of the individual ALS spot heights does not correspond between the two surveys a direct comparison of surface heights between the two datasets is not necessarily appropriate. Instead, it is necessary to create a surface, in the form of a digital elevation model (DEM), after which height changes can be mapped by comparing surfaces. In this instance the height changes will provide an insight into the magnitude and distribution of errors associated with the use of ALS data. Where a pre-mining DEM is compared to a post-mining DEM the results can be interpreted as a map of the subsidence that has occurred between the interval defined by the acquisition of both datasets.

Within this process there are a number of interrelated considerations that can be addressed through the comparison of the two presubsidence baseline surveys from 2003 and 2005. These considerations include:

1. the density and coverage of the original point data,

2. the choice of DEM resolution and interpolation method; and,

3. the spatial distribution of the errors relative to terrain (with the terrain information derived from the baseline DEMs themselves).

A general overview of the method employed to determine ALS data quality and identify sources of uncertainty is shown in Figure 2. Following the evaluation of data quality using the two baseline surveys a preliminary subsidence map is presented using a third, post-subsidence ALS survey.

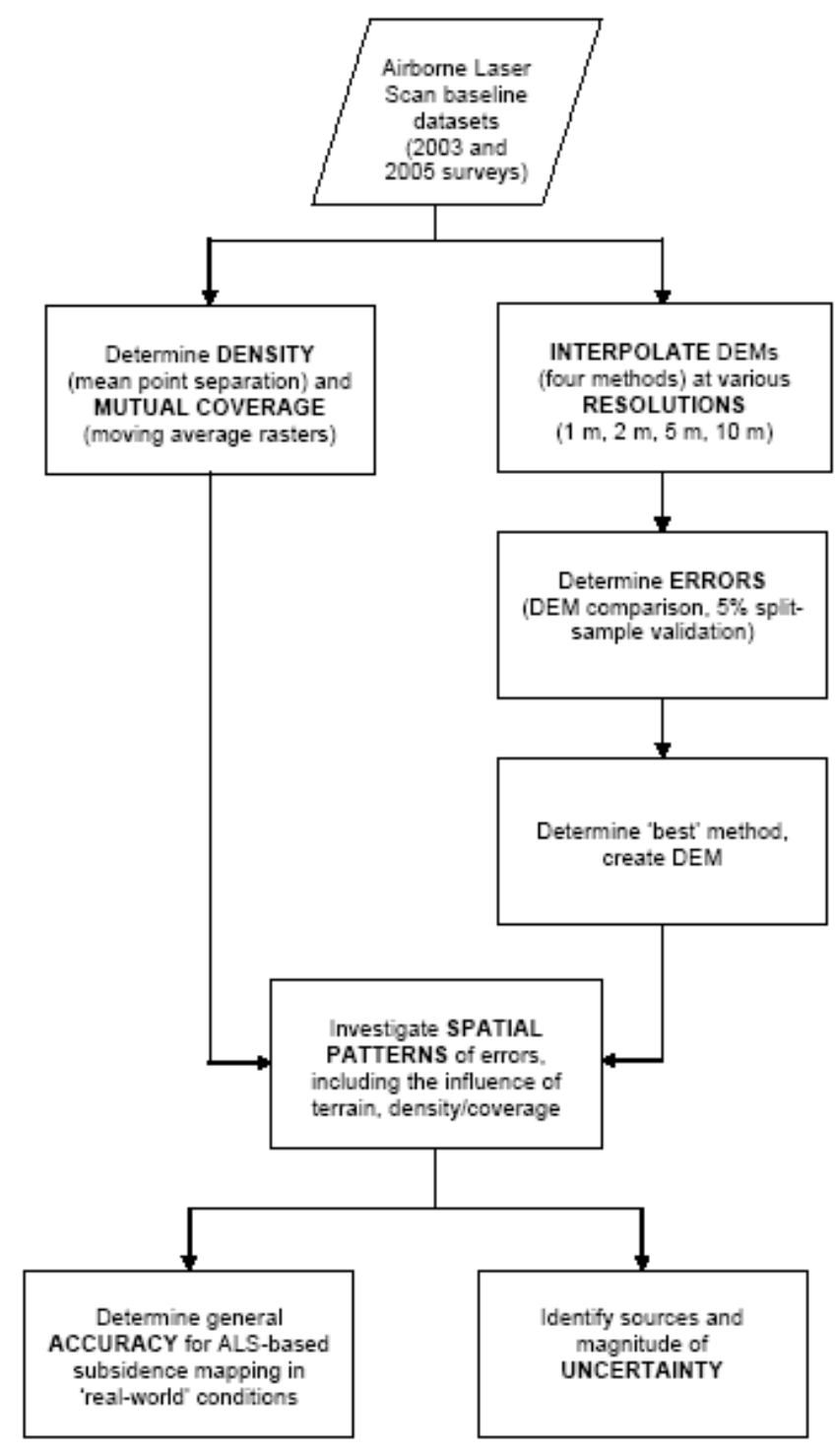

Figure 2. Overview of methods. 


\section{Density and coverage}

It is important to consider the density of the raw data points for interpolation purposes because the true horizontal resolution of the data is a function of the spacing of the original data points, rather than the resolution of the final DEM (Pilesjö et al., 2006). When evaluating ALS data for urban mapping, Smith et al. (2005) found that using a spatial resolution that most closely matched the original point spacing produced the least errors. An understanding of the original point spacing can therefore be used to determine which resolution is most suitable for interpolation purposes. The point spacing of both datasets is reported in Table 1 , and is used to determine if ALS point density is relevant to subsidence mapping potential.

The extent of coverage of the original data points within the study area was determined in order to avoid evaluating ALS data quality based on the comparison of surfaces heights in areas where the ALS point coverage is not available from both surveys. Although ALS systems can readily sample through vegetation (by sampling in the spaces within the tree canopy), given the dense vegetation cover over the study area it is likely that there are many small areas in which ground surface laser returns were not available. Therefore, to allow for the assessment of the ALS data without the added uncertainty of limited coverage, raster maps were derived indicating areas with mutual coverage from both datasets. This was done by combining raster datasets derived from each baseline point data set at $1 \mathrm{~m}, 2 \mathrm{~m}, 5 \mathrm{~m}$, and $10 \mathrm{~m}$ resolutions. The generation of the mutual coverage raster datasets is demonstrated in Figure 3.

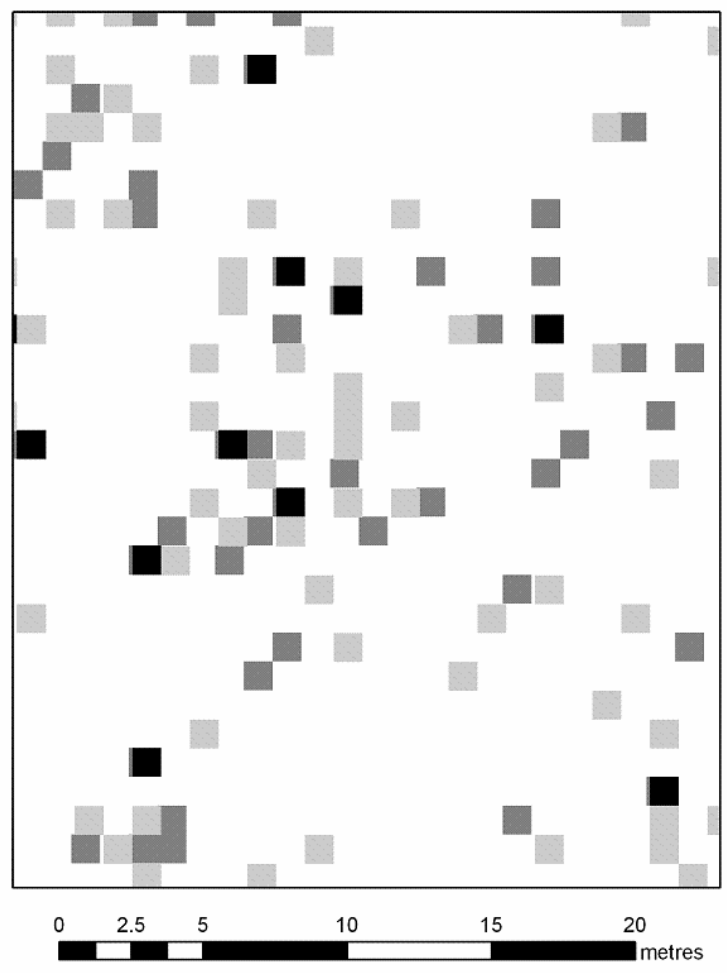

Figure 3. Derivation of the mutual coverage rasters. The figure shows a small subset of the $1 \mathrm{~m}$ rasters depicting coverage for each baseline layer (baseline 2003 as light grey, baseline 2005 as dark grey). Blank (white) areas correspond to grid cells in which no ALS source points occur. Black cells indicate mutual coverage (i.e., that ALS points from both baseline datasets occur within that cell), and were formed by combining the two $1 \mathrm{~m}$ baseline rasters. 


\section{Interpolation and resolution}

The choice of interpolation method and pixel resolution can have a significant impact upon the accuracy of the DEM surface (Smith et al., 2005). Therefore, a variety of interpolation methods were trialled to ensure that the evaluation of data quality (i.e., subsidence mapping potential of ALS data) was not unduly affected by the shortcomings of a single technique. There are numerous evaluations of interpolation methods in the literature, and the aim here is not to determine which is most appropriate for subsidence mapping because the choice of interpolation method is more often than not determined by the available computational resources and software. Instead, the main purpose of trialling a variety of interpolation methods is to quantify the magnitude of possible interpolation errors associated with ALS-based subsidence mapping.

In selecting potential interpolation methods, preference was given to approaches that are relatively straightforward and accessible. This is important so that their operation can be understood by the relevant decision makers, and so that they can be implemented using commonly available software packages. Three contrasting approaches were used involving four different methods:

1. two local, exact linear interpolation methods (modified Shepard's and inverse distance weighted),

2. triangulation with linear interpolation and subsequent conversion to DEM, and

3. moving averages.

The use of inverse distance weighted interpolation is well documented (Burrough and McDonnell, 1998) and commonly used for DEM generation, while the modified Shepard's technique is well suited to irregularly spaced data (Shepard, 1968; Renka, 1988) such as ALS data. The inverse distance weighted surfaces were derived using the freely available SAGA GIS $2.0 \mathrm{~b}$ (with settings of power 2, radius $12 \mathrm{~m}$ ). The modified Shepard's surfaces were derived with the default Surfer 8 settings (no smoothing). Triangulation is a versatile and useful method of interpolation, particularly because it is also applicable to contour data (ALS data are not always provided as points) as well as scattered points, and it represents steep and varied terrain well. DEMs based on triangulated surfaces were derived with ArcMAPтм 9.1. The moving average method was trialled because it potentially offers the benefit of 'averaging out' horizontal and vertical errors in the ALS data at the expense of surface detail. It was implemented using the neighbourhood statistics function in ArcMAPTM 9.1, wherein the GIS was used to calculate an average height value of the surrounding area for each pixel. As such, this is not a true interpolation method and suffers from problems of not providing height estimates for areas without coverage. Therefore, while it is useful for evaluating ALS suitability for subsidence mapping, in cases where ALS data are very irregular and contain gaps, moving averages may not be ideal for surface generation.

ALS data are commonly interpolated at high resolutions, such as 1 or $2 \mathrm{~m}$, in order to exploit the point density of the data for representing the terrain. from subsidence mapping, however, it may be worthwhile also considering lower resolutions both for computational ease and because a more generalised surface may provide more accurate height change measurements (due to the potential averaging out of instrumental errors). Therefore, to evaluate the effect of resolution on the capacity of ALS to map subsidence, the data were interpolated at $1,2,5$, and $10 \mathrm{~m}$ pixel sizes.

\section{Spatial patterns}

Spatially varying aspects of either the data or the surface in the study area may contribute to the error and uncertainty in the results of subsidence mapping. Terrain, for example, is known to have an effect on errors in 
ALS data, where sloped and varied terrain is associated with larger errors (Cobby et al., 2001, Latypov 2002). In the present study the standard deviation of height values over a local area was used to quantify terrain 'roughness', and its potential effect on mean absolute error (for height change analyses) was quantified through correlation.

\section{Quantification of ALS errors}

Interpolation errors and instrumental errors in the two baseline datasets were quantified through:

1. The comparison of the DEMs for the 2003 and 2005 baseline datasets. This was done under the assumption stated earlier that there should be negligible surface height change between the two datasets. As outlined previously, only areas with mutual coverage are considered in the evaluation of the baseline DEM surfaces for error quantification purposes.

2. Split-sample validation (Smith et al., 2005), in which 5\% of the source points are excluded from the interpolation process and the heights of these points are then compared with the heights of the interpolated surface. Split-sample validation was performed within and between the 2003 and 2005 baseline datasets. When performed using both the DEM and the points from within the same baseline dataset, the $5 \%$ splitsample validation results can be taken as a measure of the interpolation error. The split-sample validation results between baseline datasets (that is, the 2003 DEM compared to the 5\% 2005 original ALS points and the 2005 DEM compared to the 2003 points) gives an indication of overall height differences between repeat surveys. It is necessary to quantify this error, which is in part related to the instrumental accuracy of the laser scanner, because it will contribute to the magnitude of the vertical change in the subsidence map.

Errors were quantified using the mean of the absolute errors and also the standard deviation of the mean absolute errors ( $\mathrm{Li}, 1988$; Desmet, 1997). The mean was also considered in order to evaluate potential bias in the errors. The root mean square error, which is traditionally used to measure DEM errors, was not used due to the shortcomings outlined in $\mathrm{Li}(1988)$ and Weng (2002), which include the requirement of a zero mean error. Moreover, the spatial pattern of errors and the relationship between spatially variable factors such as terrain and point density were of greater interest than a single measure of the overall error between datasets.

\section{Results}

\section{Density and Coverage}

The density of the ALS data points for both baseline surveys was evaluated by counting the number of ALS points within each $10 \mathrm{~m}$ by $10 \mathrm{~m}$ pixel (Figure 4). The mean point spacing, shown in Table 1, of $1.69 \mathrm{~m}$ (2003 survey) and $1.85 \mathrm{~m}$ (2005 survey), corresponds to a count of roughly six points per $10 \mathrm{~m} 2$ pixel. Despite the ability of ALS systems to pass through vegetation cover (Ackermann, 1999), the density of the baseline survey points shows considerable spatial variability and there are numerous areas with no coverage (blank pixels in Figure 4). Calculations of subsidence for areas with little or no representation will be subject to high levels of uncertainty, which can be defined as a doubt to the veracity of value at a given location (Wechsler, 2003).

Given that the ALS data from the two surveys is sometimes inconsistent, it is not surprising that rasters combining the coverage of the two baseline surveys (hereafter referred to as mutual coverage rasters) contain numerous gaps. Figure 5, which shows the mutual coverage of the baseline data at $2 \mathrm{~m}$ resolution, derived 
from the moving average rasters, indicates that the distribution of ALS points is sparse in places. Even at $10 \mathrm{~m}$ resolution (not shown), there are some areas in which coverage from both datasets is lacking. When expressed as a percentage of the total study area, it is evident that the mutual ALS coverage between the two surveys is far from consistent. At $10 \mathrm{~m}$, the coverage is $96 \%$, at $5 \mathrm{~m} 72 \%, 2 \mathrm{~m} 17 \%$, and at $1 \mathrm{~m}$ the area of mutual coverage is $2 \%$ of the study area. This means that, for subsidence mapping at $1 \mathrm{~m}$ resolution only $\sim 2 \%$ of the pixels in the final subsidence map are based on actual surface observations, with the rest derived from interpolated values and are therefore subject to varying levels of uncertainty.

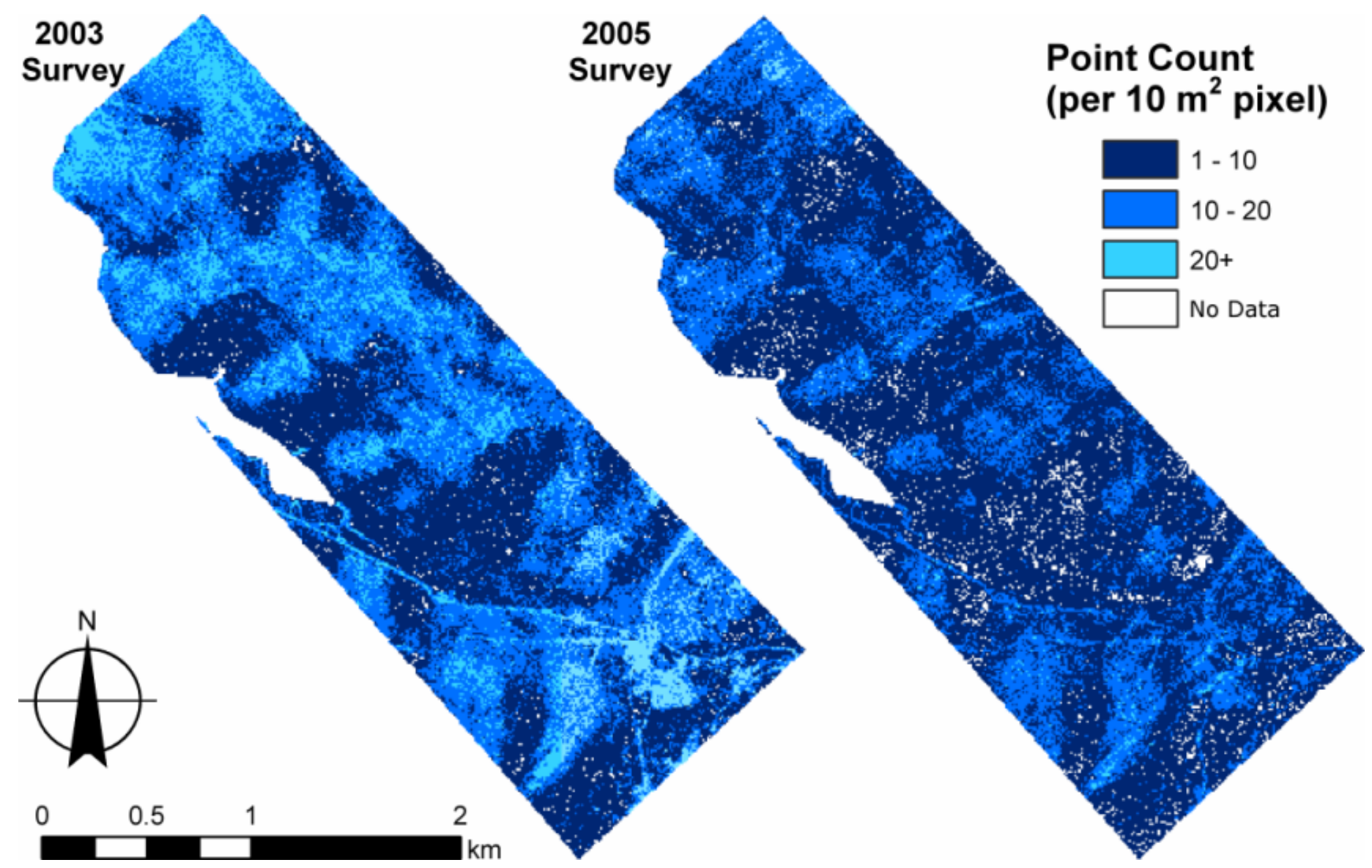

Figure 4. ALS point density for the baseline surveys. The density was derived by counting the number of ALS point within each $10 \mathrm{~m} 2$ pixel. Blank cells indicate a lack of ALS coverage, and are evident in both surveys. Areas with little or no representation will lead to uncertainty in the final subsidence map. 


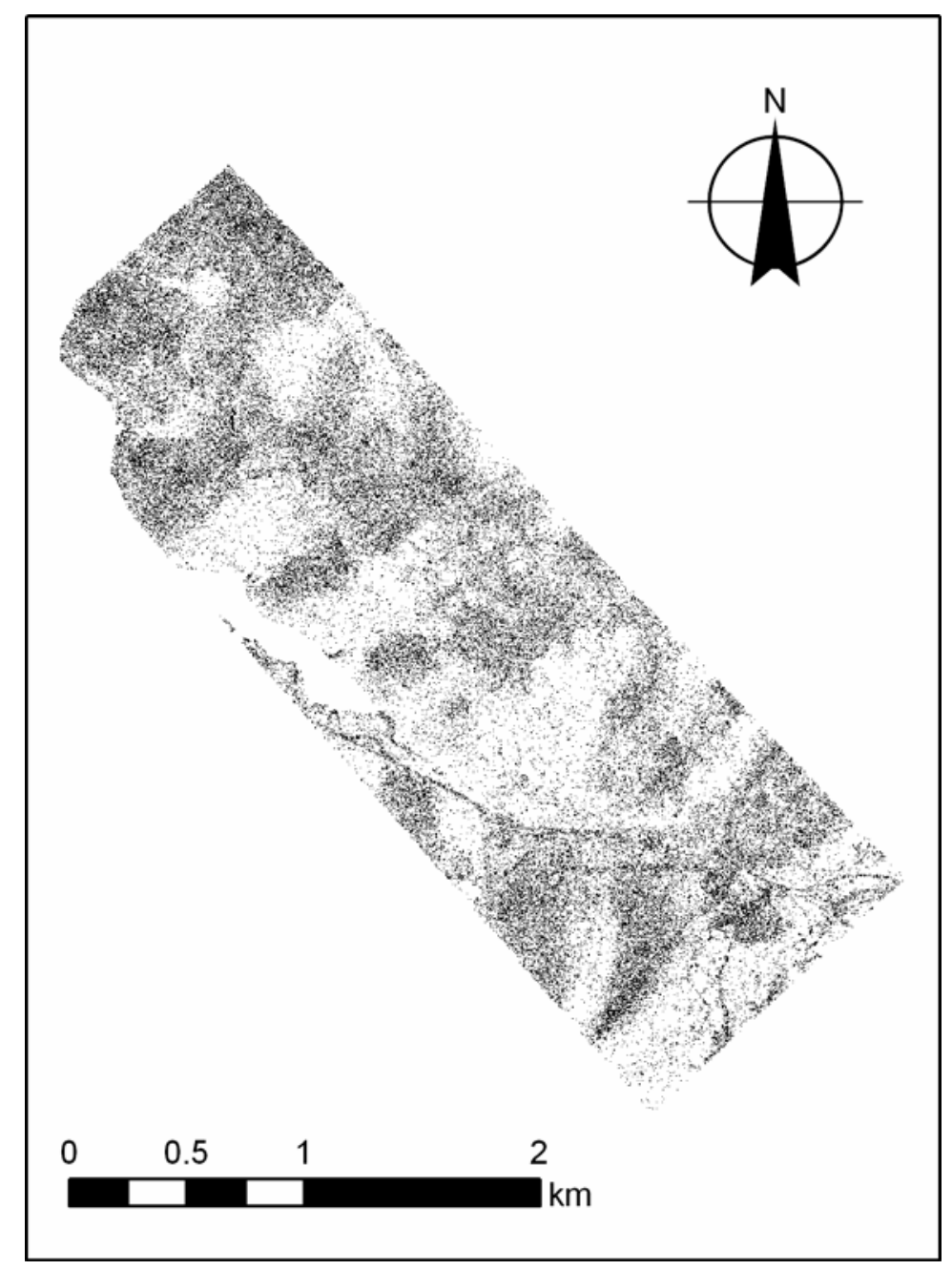

Figure 5. Mutual coverage of the baseline datasets at 2 $m$ resolution. Note how sparse the data are at this resolution. To avoid the impact that errors due to poor coverage may have on the evaluation of the ALS data, only cells with coverage from both baseline datasets were used in the evaluation of ALS data quality based on the comparison of baseline DEMs.

\section{Interpolation and Resolution}

Table 2 shows the results of the data quality assessment, as represented by the mean and standard deviation of the mean absolute error and the mean error. The results for all four interpolation methods are presented, though for the moving average split-sample validation was not performed at $1 \mathrm{~m}$ and $2 \mathrm{~m}$ resolutions because too few of the $5 \%$ sample points coincided with the raster coverage.

\section{DEM Comparisons}

From the DEM comparisons, errors were sampled using approximately 50,000 points that coincide with areas of mutual coverage from both DEM rasters. A number of points relevant to the use of ALS data for subsidence mapping are immediately evident:

1. As outlined by Smith et al. (2005), the best results are achieved when DEM resolution matches the average point separation of the original data points. This is evident here in that there is little or no improvement in the mean and the standard deviation of the absolute errors when $1 \mathrm{~m}$ pixels are used 
instead of $2 \mathrm{~m}$ pixels. Both pixel sizes approach the point separation of the raw data (1.69 $\mathrm{m}$ for the 2003 data and $1.85 \mathrm{~m}$ for the 2005 data);

2. When using resolutions that approach the point separation of the raw data, the chosen interpolation method has a minimal impact on the magnitude of the errors. from the $1 \mathrm{~m}$ DEMs, the mean absolute errors range from $0.23 \mathrm{~m}$ (with triangulation) to $0.26 \mathrm{~m}$ (with moving averages), and at $2 \mathrm{~m}$ resolution they range from $0.23 \mathrm{~m}$ (triangulation) to $0.29 \mathrm{~m}$ (modified Shepard's and moving averages); and

3. At lower resolutions $(5 \mathrm{~m}$ and $10 \mathrm{~m}$ ) the interpolation method has a greater impact. Methods such as triangulation, and to a lesser extent inverse distance weighting, result in a small increase in mean absolute error with larger pixels, while other methods (moving averages, modified Shepard's) produce larger errors.

Overall the comparison of the two DEMs suggest that, at least in this instance, ALS data can offer an average accuracy of $\sim 0.25 \mathrm{~m}$ for coalmine subsidence mapping. For all interpolation methods there appears a consistent bias in the mean errors of $\sim 0.15 \mathrm{~m}$, which is examined further in a later section on spatial patterns. Of the four interpolation methods trialled here, the use of triangulation, with subsequent conversion into a DEM, is the best performing method of surface generation.

\section{Split-Sample Validation}

As with the DEM comparisons, the split-sample validation results (within each dataset) indicate that pixel size has a greater influence on mean absolute errors than interpolation method. At $1 \mathrm{~m}$ resolution the mean absolute error is approximately $0.20 \mathrm{~m}$, while at $10 \mathrm{~m}$ the error is roughly $0.70 \mathrm{~m}$. The mean absolute error varies little between the two baseline datasets, and both display no bias in the errors as evidenced by mean errors close to zero at all resolutions. This suggests that the small reduction in raw point average spacing in the 2005 data (1.85 m compared to 1.65 ) has no noticeable effect on mean absolute error.

The comparison of the baseline DEMs to the 5\% split-sample ALS points extracted from the other baseline dataset returns mean absolute errors that are consistently higher than the corresponding split-sample analyses performed within each baseline dataset (Table 2). This is expected, because the split-sample validation between baselines incorporates both an interpolation error and a further instrumentation error associated with the second survey. However, the magnitude of the increase in mean absolute error when compared to the 'within' survey split-sample validation, which can be assigned to instrumental error, is small. It is less than $0.10 \mathrm{~m}$ in all instances, which conforms to the expected instrumental accuracy of ALS data. The increase in mean absolute error relative to the interpolation error alone (determined from the split-sample validations within each baseline dataset) is inversely proportional to pixel size, indicating that increasing the pixel size can 'average out' part of the instrumental error by sampling multiple ALS points within each grid cell.

\section{Spatial Patterns}

The DEMs derived using triangulation were used to examine the spatial distribution of height errors between the two baseline datasets. Triangulation is preferred because it is computationally efficient and commonly available in many software packages, and it has consistently yielded better results (lower mean absolute errors) at all resolutions than the other methods. The $2 \mathrm{~m}$ resolution DEMs are used, and the results, showing the difference between the 2003 baseline and 2005 baseline DEMs, are displayed in Figure 6. The absolute errors have been grouped into the following classes for ease of interpretation: 0.00 to $0.20 \mathrm{~m}, 0.20 \mathrm{~m}$ to 0.50 $\mathrm{m}, 0.50 \mathrm{~m}$ to $1.00 \mathrm{~m}$, and $1.00 \mathrm{~m}$ and greater. The height changes shown in Figure 6 encompass nearly all of the study area and have not been restricted to areas with mutual ALS point coverage; minor sections of the DEMs in the western edge of the study area have been removed because they correspond to a water-body and cannot therefore be assumed to have been static over the two year interval between baseline surveys. Included 
in Figure 6 is a histogram of mean absolute error values for both the entire DEM coverage and, for comparison purposes, areas with mutual coverage.

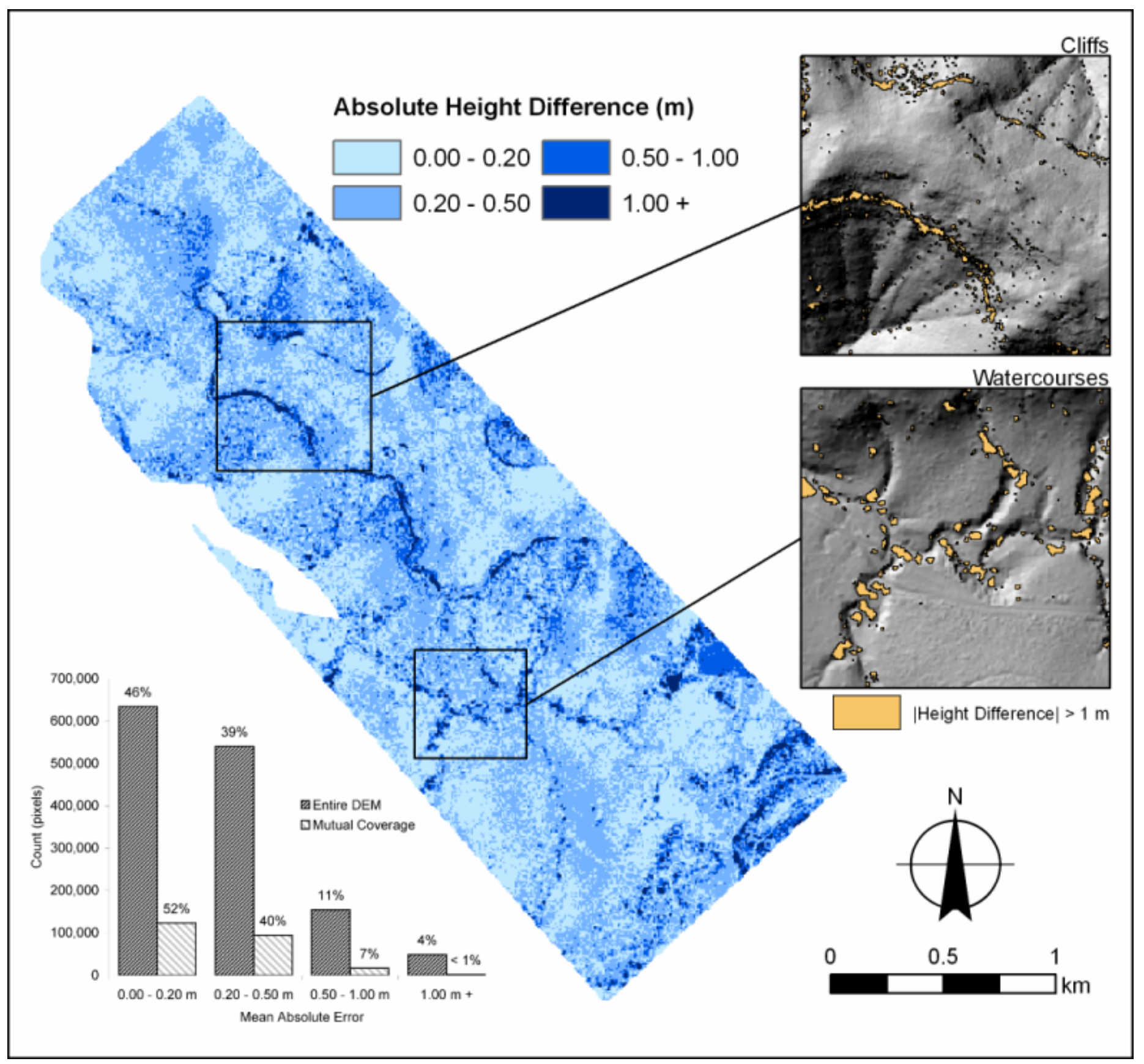

Figure 6. The distribution of errors. The errors are derived by comparing the 2003 and 2005 survey data, at $2 \mathrm{~m}$ resolution. Note the large errors in areas of steep terrain, such as along the ridge in the centre of the study site, and also within dynamic areas such as drainage channels. 


\section{Terrain}

The figure, in unison with the inset histogram, indicates that $~ 50 \%$ of the absolute errors are less than $0.20 \mathrm{~m}$, which is expected given the mean absolute average values shown in Table 2. This proportion holds for both the entire DEM comparison and the comparison using mutual coverage. The distribution of the larger errors (greater than $0.20 \mathrm{~m}$ ) is not completely random however, but is instead related to terrain. The largest errors (greater than $1.00 \mathrm{~m}$ ), in particular, are terrain dependent and often occur along cliff lines and steep slopes (see insets in Figure 6). For instance, large errors (sometimes greater than $10 \mathrm{~m}$ ) are evident along the cliffs that flank the ridge in the centre of the study area. Correlation between the standard deviation of observed heights (taken from the 2003 survey and used to represent terrain roughness) with the mean absolute error, sampled on a grid of $10 \mathrm{~m}^{2}$ cells, yields a correlation coefficient $(\mathrm{R})$ of $0.50(\mathrm{~N}=54,409)$ which is statistically significant at the $99.9 \%$ confidence level. In the lower portion of the study area, errors of several metres are evident along sections of drainage lines. In both cases (steep areas, drainage channels), errors occur because of the horizontal error in ALS point data, which can shift the boundary of steep or narrow features. Erosion or sedimentation can be ruled out as a possible explanation for the observed height changes because on these timescales they are likely to be in the order of millimetres only.

\section{Bias}

This bias described earlier may be due to an actual change of the surface between the baseline surveys (the 2005 DEM is generally lower than the 2003 DEM), or a systematic vertical offset between baseline surveys potentially associated with GPS errors during data capture or the utilisation of different ground survey calibration data. The latter is more likely, because even though the bias suggests a lowering of the surface between the two surveys, erosion of this magnitude is highly unlikely in such a highly stable area. Indeed, spatial smoothing of the errors using a $100 \mathrm{~m}$ radius circle (not shown) reveals that the bias is distributed over nearly the entire study. This suggests that it is the result of a systematic offset between surveys, since the diverse nature of the terrain would preclude uniform erosion over the entire study area. Regardless of its origin, the fact that bias exists must be acknowledged as a potential source of uncertainty with subsidence mapping based on ALS data. This bias will lead to the overestimation of mean absolute error, and therefore in instances where this bias does not exist, greater accuracy can be expected from height-change measurements derived from ALS-data.

\section{Subsidence Mapping}

A preliminary subsidence map (Figure 7) was created using a third ALS data set, collected during December 2005 , which was compared with the most recent pre-mining dataset (the second of the baseline surveys, collected in February 2005). Subsidence mapping was performed using surfaces derived through triangulation and subsequent conversion to a $2 \mathrm{~m}$ DEM. In Figure 7 the subsidence trough is clearly evident, which attests to the suitability of ALS data for this task. The general extent and magnitude of the subsidence trough is readily discernable, despite the prevalence of vertical errors throughout the entire unfiltered data set. Extremely large errors are evident in association with steep terrain, as expected from the data quality analyses outlined earlier. Positive height changes, which cannot be attributed to subsidence and must therefore be largely erroneous, are also widespread due to both the presence of steep terrain and the instrumental vertical and horizontal accuracy of ALS data. Figure 8 shows some sample profiles across the subsidence trough, demonstrating both that subsidence has occurred in the study area and that it is detectable with repeat ALS surveys, even in rough terrain. Figure 8a shows a profile which is not unduly affected by vertical errors associated with the cliffs over the longwall, while Figure $8 \mathrm{~b}$ shows a profile which coincides with the cliffs. The impact that the steep terrain has, in terms of errors in the subsidence profile, is clearly evident. Nevertheless, the general shape and magnitude of the subsidence trough is clearly evident. 
Table 2. A comparison of the performance of interpolation methods and resolution.

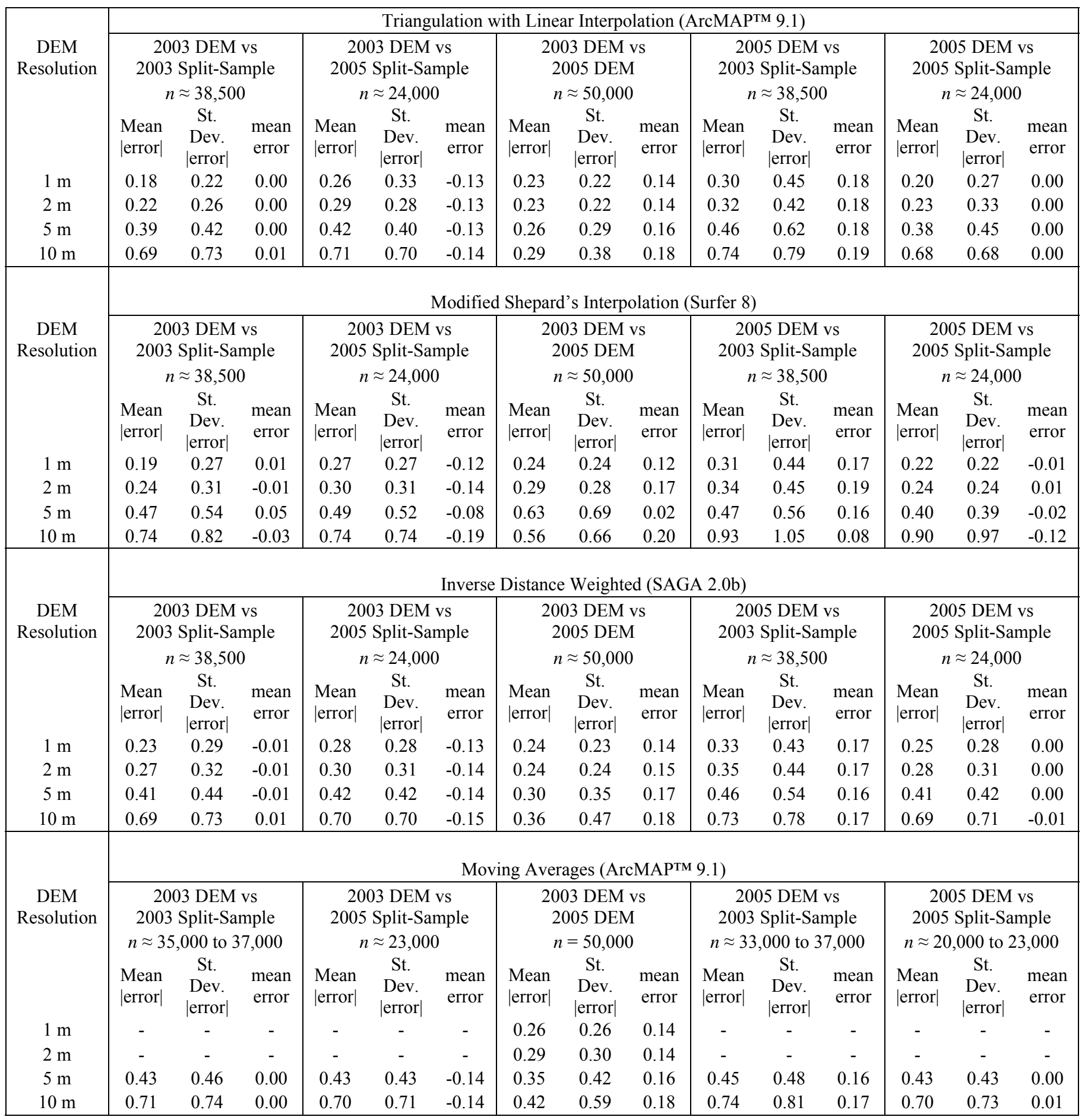




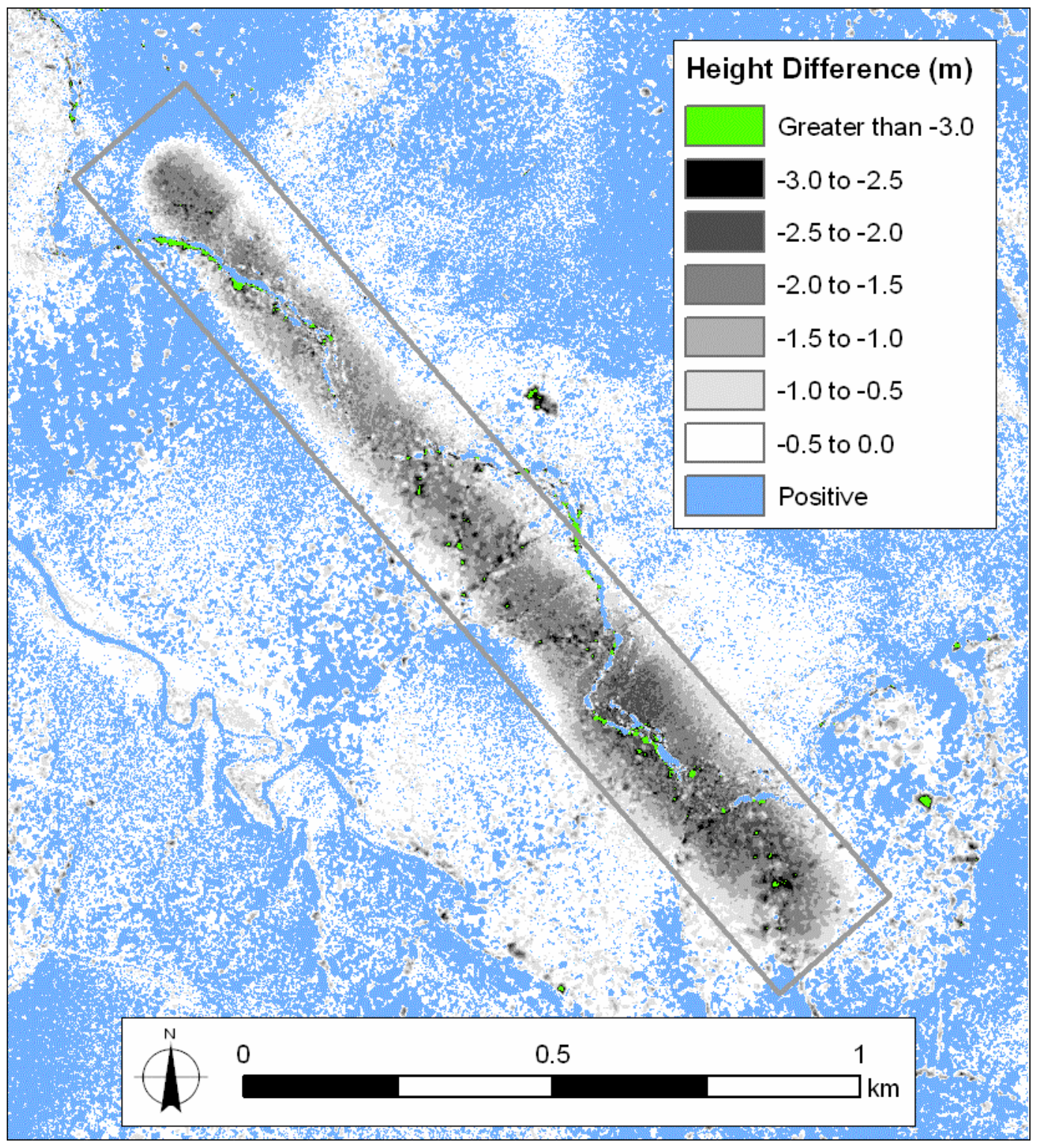

Figure 7. Preliminary subsidence map. A post-mining ALS survey, conducted during December 2005, was used with the February 2005 baseline survey to derive this subsidence map. Note that the coverage of the datasets has been extended beyond that of the original study site used for data quality evaluation. The subsidence trough is clearly visible over the mined longwall panel, demonstrating the suitability of ALS data for subsidence mapping, even in challenging terrain such as this. The spatial extent and magnitude of the mapped subsidence conforms well to expectations. However, numerous vertical errors are also evident in the abundance of positive height changes and also the large negative changes associated with steep features such as the cliffs along the central ridge. Methods are required to accurately filter these errors from the mapped product. 


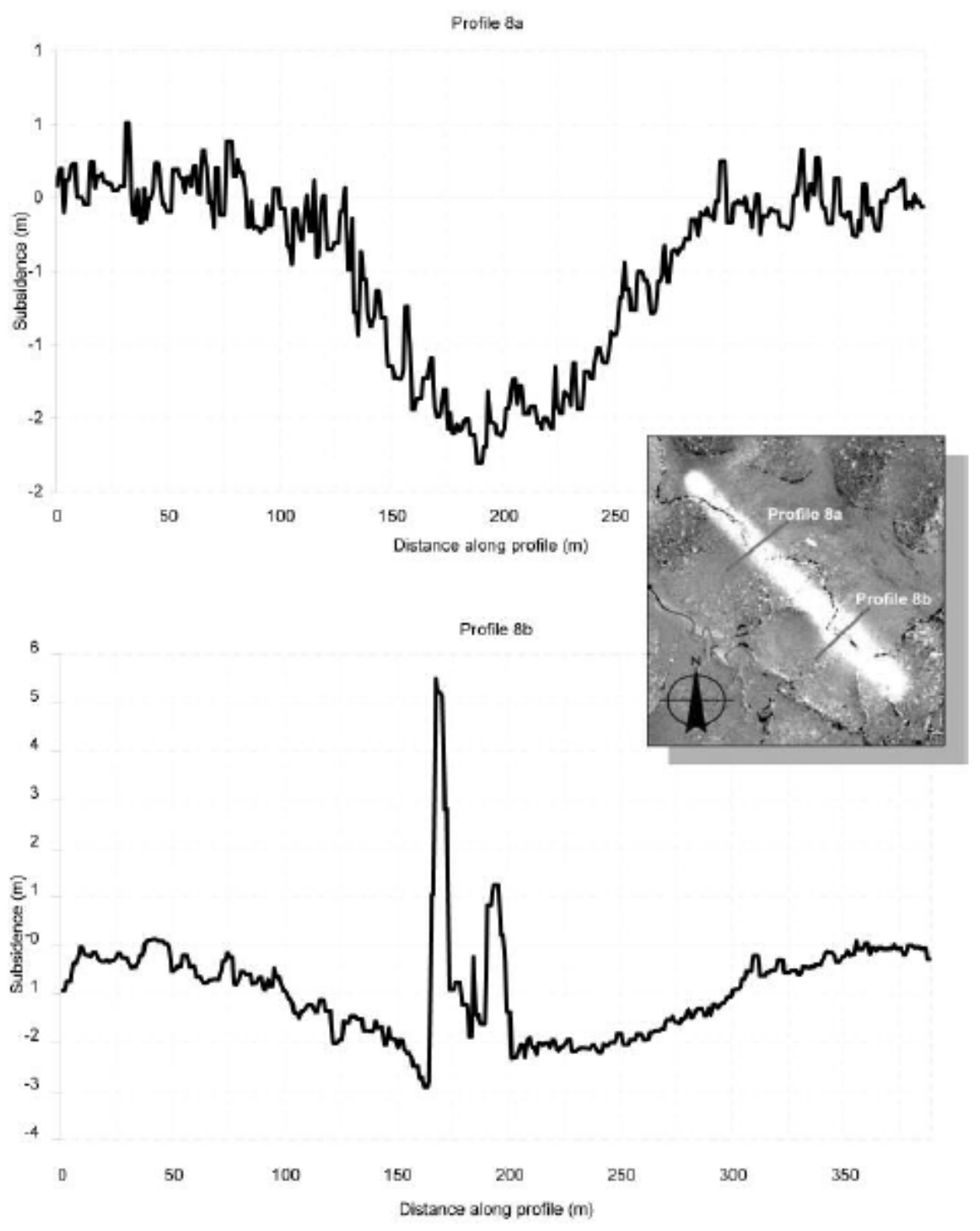

Figure 8. Subsidence Profiles. The figure shows two profiles over the subsidence trough, which was generated using the 2003 baseline and 2005 post-mining ALS surveys. The profiles demonstrate the ability of ALS surveys to detect coalmine subsidence. Although vertical errors are evident in both profiles, particularly profile $8 \mathrm{~b}$ because of the presence of a cliff line, the magnitude and extent of the subsidence trough is clearly evident. 
The inaccessibility of the study area did not permit the collection of a ground-based survey across the main subsidence area; however, it was still possible to quantify vertical errors because the coverage of these two datasets extends well beyond the area of the expected subsidence trough. Once again, the assumption that no systematic or large-scale changes in surface height occurred between surveys, outside of the main subsidence zone, was adopted, and any height changes observed in those areas were interpreted as vertical errors (Figure 9). Three areas were selected, all of which were more than $500 \mathrm{~m}$ from the longwall and the associated subsidence trough. Although some far field horizontal or even vertical subsidence could be expected in these areas, the magnitude of the changes are minimal, particularly when compared to the instrumental accuracy of the ALS data, and will therefore not affect the analysis of height errors in these three subsidence 'free' areas. The mean absolute errors in these three areas, as numbered in Figure 9, are $0.29 \mathrm{~m}, 0.34 \mathrm{~m}$, and $0.25 \mathrm{~m}$ respectively, which are slightly greater but of the same order of magnitude as the mean absolute error derived from the baseline datasets (Table 2). The mean error, which is an indication of bias, represents a difference of $0.01 \mathrm{~m}, 0.18 \mathrm{~m}$, and $0.16 \mathrm{~m}$ in the three assessment areas. This implies that the post-mining surface in these areas has increased in height relative to the 2005 baseline survey, which is unlikely, and therefore suggests some offset or bias between the two surveys.

Although access difficulties prevented comprehensive ground surveying, limited data (isolated points) were collected within a few months of the post-mining survey. These data were collected by colliery staff using static differential GPS methodology (close to $2 \mathrm{hr}$ occupation) for 11 points within the study site with a vertical and horizontal accuracy better than $25 \mathrm{~mm}$. For the post mining survey the mean difference between the ground control data and the $2 \mathrm{~m}$ TIN-derived DEM is $0.24 \mathrm{~m}$ (Min. - 0.09 , Max. 1.69, S.D. 0.51). The removal of a single outlier (difference of $1.69 \mathrm{~m}$ ), situated at the northern end of the prominent ridge over the study site resulted in a mean differences of $0.10 \mathrm{~m}$ (Min -0.09, Max. 0.78, S.D. 0.24). This conforms to the quoted accuracy of the ALS survey data, and suggests that overall the survey process does relatively well in mapping the ground surface, even in difficult terrain. Comparisons to DGPS ground control points were also performed for the 2003 baseline survey, even though it was not used for the generation of the subsidence maps and profiles shown in Figures 7 and 8, and yielded similar accuracies (Mean -0.06, Min. -0.21, Max. 0.58 , S.D. $0.26, \mathrm{~N}=7$, outlier excluded). Unfortunately, similar ground control data were not available for the 2005 baseline survey due to ground access difficulties. 


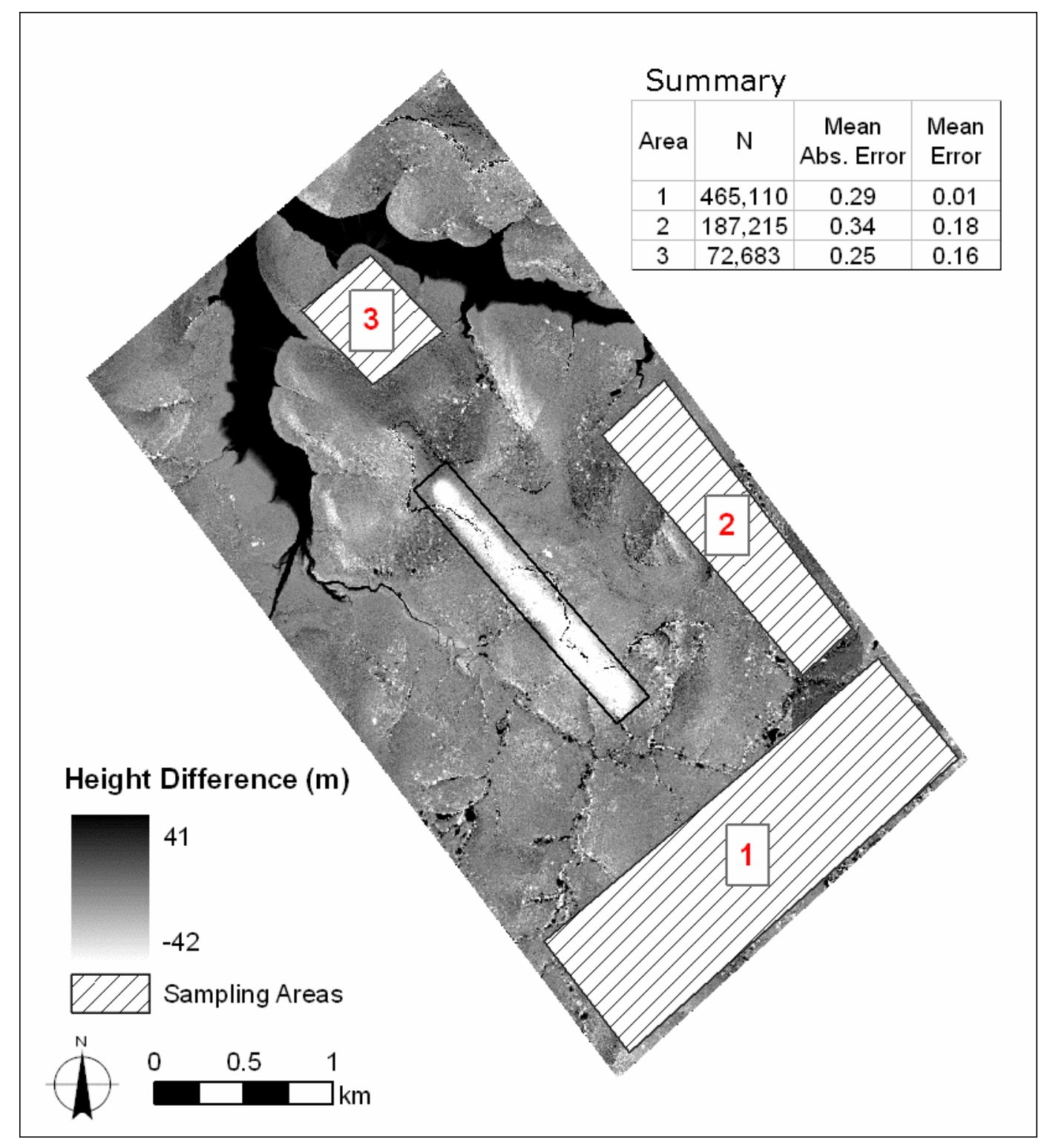

Figure 9. Sampling areas for error analysis and the associated mean absolute and mean errors. Three areas that are distant from the subsidence trough (indicated in the centre by the white shading and the outline approximating the longwall location) were chosen. Height differences for these areas were considered as errors, based on the assumption that vertical changes in these areas due to either subsidence or natural processes should be minimal or non-existent (see inset Table). The results are consistent with those derived from the data quality results outlined earlier for the two baseline datasets, and suggest the need to acknowledge the presence of vertical errors in the mapped product. 


\section{Discussion}

The potential for ALS data to map coalmine subsidence was evaluated by comparing two pre-mining surveys for what is considered an extremely challenging study site. Height changes between the two surveys were primarily considered as 'errors' and used to gauge the accuracy and quality of the data and associated methods. From the results presented here a number of observations have been made, and subsequently, some statements about a proposed methodology for mapping coalmine subsidence using ALS data are proposed.

This study involved a complex site with very rough terrain and dense vegetation and the baseline ALS data exhibited a mean absolute error of $0.23 \mathrm{~m}$ when triangulation was used for DEM generation. For many longwall coalmining operations, this level of error is more than acceptable when assessing domain level or regional subsidence movements. This is particularly the case when it is acknowledged that a systematic offset between surveys may have served to increase the magnitude of errors, and also that for much of the study site the mean error was less than $0.23 \mathrm{~m}$. Despite these errors, the preliminary subsidence map shown in Figure 7 demonstrates that ALS data is a valuable and powerful tool for subsidence mapping. The extent of the subsidence trough can be readily discerned, and initial attempts at removing noise through the use of spatial averaging has yielded promising results. Further work is continuing with the aim of developing appropriate methodology for the removal of vertical errors, but even at this stage it is apparent that ALS data can provide valuable insights into subsidence movements due to its large spatial coverage and horizontal resolution.

Nevertheless, at this stage assessment of watercourses, steep slopes, and cliff areas should be treated with caution during height change analyses using ALS, not only because of their potential for instability, but because the horizontal accuracy of ALS data used is generally not suitable for the accurate mapping of steep or narrow features (French, 2003). The application of ALS data to subsidence mapping in urban areas may suffer from the same problems; the steep edges of buildings will lead to large errors while urban developments will cause surface height changes that will confound the measurement of mine subsidence. Non-urban areas that are likely to be problematic can be determined using the slope classification and stream network delineation features common to many GIS software packages. Alternatively, the analysis of multiple baseline surveys, as performed here, will provide the best guide to potential areas of uncertainty and error in subsidence mapping, and reveal the magnitude of any non-subsidence related surface change, whether real (due to surface processes such as erosion, deposition, or anthropogenic development) or apparent (due to bias and systematic errors between surveys). ALS surveys undertaken for longwall mining operations will potentially extend into the area of adjacent planned longwalls, thereby providing baseline surveys for nearby, subsequent longwalls at little extra cost. However, the subsidence effects from previously mined panels will need to be quantified and removed as part of the process.

At this relatively early stage in the development of ALS based analysis it seems unlikely that the particularly problematic phenomenon of 'upsidence', which refers to the reduced magnitude of vertical subsidence at the base of valleys and steep terrain (Holla, 1997), can be detected using ALS data. The magnitude of upsidence reported previously in the state of NSW is generally at the sub-metre level (Holla, 1997; Waddington and Kay, 2003), and may therefore prove difficult to detect and map using ALS data. The main limitation, however, is not the vertical accuracy of the ALS data, but the tendency for large errors to occur in and around steep terrain and narrow features. As outlined in Figure 6, large errors tend to occur in watercourses because of their narrow morphology and potential for erosion and sedimentation, which coincides with the typical location of upsidence. 
The mapping of horizontal ground movement associated with subsidence also seems unfeasible using ALS data. Horizontal ground movements are known to exceed vertical ground movement in areas distant from mine workings, but are typically in the order of centimetres (Holla and Barclay, 2000). It is unlikely that ALS data of the type used in this study can offer any potential for mapping horizontal movements because of the relatively large (up to $55 \mathrm{~cm}$ according to sensor specifications) horizontal error in the point data. Even if a recognised benchmark could be identified within the surveyed area, the horizontal inaccuracy of the ALS data would prevent its use for quantifying horizontal movements. It is likely, however, that there will be development (at the instrumental level) in the use of ALS datasets for defining planimetric features in the future.

In summary, the main recommendations to be derived from the results are that when using ALS data for subsidence mapping:

1. The ALS data should be interpolated at the appropriate resolution, which should match the mean point separation of the raw data,

2. Exercise caution mapping subsidence in areas with reduced coverage, or which are known to contain steep or changeable features,

3. Consider methods to determine potential bias between surveys and identify areas which are prone to error, such as multiple baseline surveys or an examination of height changes outside of the expected subsidence area, and

\section{Conclusion}

When compared to traditional survey methods, the benefits of using ALS data to map coalmine subsidence include:

1. easier site access, especially in areas of rugged terrain and heavy vegetation

2. reduced survey resources required and improved safety, and

3. a more comprehensive mapped product.

However, vertical accuracy is considerably reduced and poor horizontal accuracy may limit the ability to map upsidence and horizontal movements. Nevertheless, the results shown here have demonstrated that repeat ALS surveys are a powerful tool for subsidence mapping, and that with appropriate precautions ALS data can be used to derive valuable insights into the magnitude and spatial extent of subsidence that are not readily achieved using traditional ground-based surveys.

The straightforward method of comparing a pre- and post-subsidence DEM will yield a useful subsidence map with acceptable vertical accuracy and considerable potential for the study of subsidence patterns and the validation of predictions, but further work is required on the removal or minimisation of vertical errors in the results. Future research will address the development and assessment of optimal ground calibration techniques based on the two methods commonly in use; the first uses a localised region of high density ground points (for example, a $100 \mathrm{~m} \times 100 \mathrm{~m}$ area with ground calibration points surveyed on a $5 \mathrm{~m}$ grid), while the second method (which was used with the data in this case study) uses a smaller number of discrete ground surveyed calibration points evenly distributed throughout the capture area. The optimisation of ground calibration methods should reduce or possibly remove the height bias observed between the datasets presented here. Other proposed research will compare the performance of ALS subsidence mapping in more amenable terrain, 
in which ground surveys can be undertaken and the topography is not as rough or heavily vegetation, with the results presented here.

For an economic perspective it must be acknowledged that the use of ALS methods for subsidence monitoring is substantially more expensive than traditional ground based methods. This is because ground based survey techniques generally focus on a small number (usually 1 to 3 ) of survey lines as well as a selection of discrete points. However, while these techniques yield high accuracy results over very isolated areas within the subsidence zone and surrounds (typical coverage $<5 \%$ of affected area), ALS provides $100 \%$ coverage over the affected areas and surrounds, albeit at lower accuracies. This comprehensive coverage provides subsidence data analysts a complete picture of the subsidence zone and is therefore more useful for decisionmaking purposes.

\section{Acknowledgements}

The authors would like to thank the following individuals for providing data, information, and advice: Mark Freeburn from AAMHatch for information on data collection, the ALS sensors, and for providing the relevant metadata, Rod Doyle for depth of cover data, Richard Walsh for operational data and comments on the manuscript and Dr. Alexandra Golab for her advice and comments on various drafts. The authors also gratefully acknowledge funding from the Australian Coal Association Research Program (Project C14031), which made this research possible, and the helpful comments of two anonymous reviewers.

\section{References}

ACKERMANN, F., 1999, Airborne laser scanning - present status and future expectations. ISPRS Journal of Photogrammetry and Remote Sensing, 54, 64-67

Bell, F.G., StaCey, T.R., GENSKE, D.D., 2000, Mining subsidence and its effect on the environment: some differing examples. Environmental Geology, 40, 135-152

Burrough, P.A. AND MCDonnell, R.A., 1998, Principles of Geographical information Systems. (Oxford University Press), 333 pages

CoBby, D.M., MASON, D.C., DAVENPORT, I.J., 2001, Image processing of airborne laser altimetry data for improved river flood modelling. ISPRS Journal of Photogrammetry and Remote Sensing, 56, 121-138.

DESMET, P.J.J., 1997, Effects of interpolation errors on the analysis of DEMs. Earth Surface Processes and Landforms, 22, 563-580

FRENCH, J.R., 2003, Airborne lidar in support of geomorphological and hydraulic modelling. Earth Surface Processes and Landforms, 28, 321-335

Glenn, N.F., StreutKer, D.R., Chadwick, J., Thackray, G.D., Dorsch, S.J., 2006, Analysis of LiDARderived topographic information for characterizing and differentiating landslide morphology and activity. Geomorphology, 73, 131-148

HAWORTH, R.J. 2003, The shaping of Sydney by its urban geology. Quaternary International, 103, 41-55 
Holla, L., 1997, Ground movement due to longwall mining in high relief areas in New South Wales, Australia. International Journal of Rock Mechanics and Mining Sciences, 35, 775-787

Holla, L. AND BarClay, E., 2000, Mine subsidence in the southern coalfield, NSW, Australia. (New South Wales Department of Mineral Resources), 118 pages.

LATYPOV, D., 2002, Estimating relative lidar accuracy information from overlapping flight lines. ISPRS Journal of Photogrammetry and Remote Sensing, 56, 236-245

LI, Z., 1988, On the measure of digital terrain accuracy. Photogrammetric Record, 72, 873-877

LOHANI, B. AND MASON, D.C., 2001, Application of airborne scanning laser altimetry to the study of tidal channel geomorphology. ISPRS Journal of Photogrammetry and Remote Sensing, 56, 100-120

McDonald, R.C., IsBell, R.F., SPeight, J.G., WALKeR, J. AND HoPkins, M.S., 1998, Australian soil and land survey field handbook. 2nd Edition. (Department of Primary industries and Energy and CSIRO Australia), 190 pages

Pilesjö, P., Persson, A., AND HARRIE, L., 2006, Digital elevation data for estimation of potential wetness in ridged fields - comparison of two different methods. Agricultural Water Management, 79, 225-247

RENKA, R. J., 1988, Multivariate interpolation of large sets of scattered data. ACM Transactions on mathematical software, 14, 139-148

SHEPARD, D., 1968, A two-dimensional interpolation function for irregularly-spaced data. Proceedings of the ACM National Conference, 517-524

Shrestha, R.L., Carter, W.E., SARTORI, M., Luzum, B.J., Slatton, K.C., 2005, Airborne laser swath mapping: quantifying changes in sandy beaches over time scales of weeks to years. ISPRS Journal of Photogrammetry and Remote Sensing, 59, 222-232

Sidle, R.C., Kamil, I., Sharma, A., Yamashita, S, 2000, Stream response to subsidence from underground coal mining in central Utah. Environmental Geology, 39, 279-291

SinGH, K.B. AND SingH, T.N., 1998, Ground movements over longwall workings in the Kamptee coalfield, India. Engineering Geology, 50, 125-139

Smith, S.L., Holland, D.A., AND Longley, P.A., 2005, Quantifying interpolation errors in urban airborne laser scanning models. Geographic analysis, 37, 200-224

ThOMA, D.P., GuPTA, S.C., BAUER, M.E., KIRCHOFF, C.E., 2005, Airborne laser scanning for riverbank erosion assessment. Remote Sensing of Environment, 95, 493-501

WADDINGTON, A. AND KAY, D., 1995. The incremental profile method for prediction of subsidence, tilt, curvature and strain over a series of panels. Conference on buildings and structures subject to ground movements, Mine Subsidence Technology Society, $5^{\text {th }}-7^{\text {th }}$ February, Newcastle. 
WADDInGTON, A. AND KAY, D., 2003, The impact of mine subsidence on creeks, river valleys and gorges due to underground coal mining operations. Australian institute of Mining and Metallurgy 2003 Coal Operators' Conference, 12-14 February 2003, University of Wollongong, 101-116

WeChSLER, S.P., 2003, Perceptions of digital elevation model uncertainty by DEM users. URISA Journal, 15, $57-64$

WENG, Q., 2002, Quantifying uncertainty of digital elevation models derived from topographic maps. In Advances in Spatial Data Handling. D. Richardson and P. van Oosterom (Ed.). (New York: SpringerVerlag), pp. 403-418

WoOlard, J.W. AND COLBY, J.D., 2002, Spatial characterization, resolution, and volumetric change of coastal dunes using airborne LIDAR: Cape Hatteras, North Carolina. Geomorphology, 48, 269-287

Young, A.R.M. (1986) The geomorphic development of dells (Upland Swamps) on the Woronora Plateau, NSW. Australia. Zeitschrift fur Geomorphologie, 30, 317-327 